This is the accepted manuscript of the article, which has been published in New Media and

Society 2019.

https://doi.org/10.1177/1461444819868686

\title{
Affective economy of national-populist images: investigating national and transnational online networks through visual big data
}

Hokka, Jenni; Nelimarkka, Matti

\begin{abstract}
In our article, we investigate the affective economy of national-populist image circulation on Facebook. This is highly relevant, since social media has been an essential area for the spread of national-populist ideology. In our research, we analyse image circulation as affective practice, combining qualitative and quantitative methods. We use computational data analysis methods to examine visual big data: image fingerprints and reverse image search engines to track down the routes of thousands of circulated images as well as make discourse-historical analysis on the images that have gained most attention among supporters. Our research demonstrates that these existing tools allow social science research to make theory-solid approaches to understand the role of image circulation in creating and sustaining national and transnational networks on social media, and show how national-populist thinking is spread through images that catalyse and mobilise affects - fear, anger and resentment - thus creating an effective affective economy.
\end{abstract}

\section{Keywords}

Affect, affective economy, Facebook, images, image circulation, nationalism, national-populism, populism, social media, visual big data

\section{Introduction}

Radical right-wing movements have become very skilful at using visual material. Working on different social media platforms, these movements reinforce the commitment of long-standing supporters and persuade newcomers to join their ranks (Doerr, 2017). So far, only qualitative research has addressed far-right images on social media and has mainly focused on small samples of certain pictures, tracing the routes of individual images (Horsti, 2016) or presenting multimodal analyses of the relationship between image and text (Doerr, 2017).

This investigation of the affective economy of national-populist images used both qualitative approaches and computational data analysis to examine the circulation of online images by national-populist groups on a larger scale than previous research. The driving research question is: In what ways does image circulation as an affective practice work as a tool for national-populist movement? We approach this question by asking: 1) Which images received the most comments and reactions, and which were the most circulated among the analysed communities? 2) What 
kinds of images received the most attention among the analysed communities? 3) Through what routes were images circulated a) transnationally and b) among local, national Facebook communities? Thus, we approach affective economy of national-populist image circulation from three different angles: by sorting out the images that have most mobilized affective attention among supporters, by analyzing the political discourse of these images and by investigating the national-populist movements' mutual connections across groups, platforms and countries.

The study was grounded in the theory of affective economy developed by Sara Ahmed (2004a; b), whose influential works have depicted how racism and extreme nationalism gain power from collective emotions and affects, such as feelings of danger, attachment and hate. These affects acquire more value through the constant repetition of the signs and figures associated. Affects do not reside in these signs but they are an effect of their circulation.

Examining images is vital to exploring the affective economy. Images can reduce complex political issues to simplistic visual frames (Zelizer, 2010: 1). Images amplify and modify affect (Proitz, 2018: 551) as audiences and users convert their affective judgements and understandings of their identities into images and associated dispositions, expressions and connections. Thus, images are not merely representations but become networks of associations and affects in time and place (Carah, 2014: 138). Images arouse discourses of shared emotions and responses, highlighting the collective dimension of affective meaning-making (Nikunen, 2015: 22). It, therefore, is important to determine the extent of the circulation of national-populist images to understand the role of social media platforms in the increasing popularity of these movements.

Although ground-breaking in cultural studies, the theory of affective economy is rightly criticised for conceptual inaccuracy (Wetherell, 2012: 156-160). Consequently, M argaret Wetherell (2012) proposed studying affect as social action. Affects should be located, 'not in endless and mysterious circulations, but in actual bodies and social actors, negotiating, making decisions, evaluating, communicating, inferring and relating' (Wetherell, 2012: 159). Image circulation, too, is an affective practice, exercised by social actors and enabled by social media platforms. Through sharing and circulating images, and commenting and reacting to the shared images, members of the national-populist Facebook groups can express their emotions and political views, express their belonging to the group, and strengthen the shared affective and political meaning-making in the group. Ahmed's (2004a; b) theory of affective economy and Wetherell's (2012) conceptualisation of affect as practice were operationalised in this study combining quantitative computational methods and qualitative approaches. The analysis demonstrated how affectivity gains force from transnational networks and how the circulation of national-populist images creates an effective affective economy.

\section{Affective economy and national-populist images}

Affectivity is a widely debated concept, with varying definitions among and within scientific fields from neuroscience to cultural studies (Nikunen, 2019). In this article, we understand affect as an immediate emotional reaction to something. This reaction is not merely biological, innate or primary but is shaped by conscious experiences and meaning-making processes. Affect is not merely an individual reaction but is influenced by cultural norms and practices and social 
structures. Affect thus has a collective dimension, visible in the ironic, hateful, fearful and compassionate responses in public debates and events (Nikunen, 2019; Wetherell, 2012: 140160).

Wetherell (2012) proposed analysing affects as practices. Identity, affect, legitimacy and social practice are closely interwoven. Affective practice is the 'moment of recruitment and often synchronous assembling of multimodal resources ' (Wetherell, 2012: 159) when humans, as both biological bodies and social actors, negotiate, evaluate, make decisions and communicate based on their personal experiences, social structures and cultural norms. Affective practices mark racial, gendered and class boundaries as emotions of fear, disgust and shame deeply intertwine with conscious and socially shared cultural and political understandings (Ahmed, 2004a; Nikunen, 2019; Wetherell, 2012).

In Ahmed's (2004a) theory of affective economy, affect becomes more powerful through circulation. The affective economy aligns signs, figures, objects and ideas, which gain affective value through circulation (Ahmed, 2004a: 67). Thus, based on signs, figures, object and ideas, affects appear in discursive form. What gives value to affect is the history of affective practice and its entanglements with other social practices and formations (Wetherell, 2012: 159). Affect thus has a historical dimension.

In political science, discussion on the role of affects and emotions has been rare, but the rise of populism has drawn attention to affectivity as the insufficiency of economic and social-structural explanations has been shown. Many studies (e.g. Crociani-Windland and Hoggett, 2012; Da Silva and Vieira 2018; Demertzis 2006) have connected the success of populism to supporters' feelings of resentment and ressentiment (on their differences, see Demertzis 2006). For example, Capelos and Demertzis (2018) investigated how the fusion of anger, fear and hope in complex blends of resentful or ressentiment-ful affectivity leads to certain political actions, such as support for populist parties. Salmela and Scheve (2017) proposed that the mechanism of ressentiment explains how negative emotions, such as fear and insecurity, transform through repressed shame into anger, resentment and hatred towards perceived 'enemies' of the self. However, Salmela and Scheve (2018) claimed that the emotional processes of right-wing and left-wing populisms' emotional processes differ from each other. According to them, right-wing populism is characterized by repressed shame that transforms fear and insecurity into anger, resentment and hatred, whereas in left-wing populism, acknowledged shame allows individuals to self-identify as aggrieved and humiliated (Salmela and Scheve, 2018). These studies on populism and affectivity, however, acknowledge but do not analyse the significance of the role of social media in the rising popularity of populism.

Populism and its definition have been debated in social sciences. There is no consensus if it is a thin or thin-centred ideology or no ideology at all but a political logic, strategy or style (M offit and Tormey, 2014). We do not view populism as an ideology but agree with Brubaker's (2017a) understanding of populism as a discursive, stylistic repertoire with certain discursive elements (e.g. majotarianism, anti-institutionalism and the claim to speak in the name of people) and a 'low style' that values simplicity over complexity, first-hand experience over expert knowledge, and attention and provocation over politeness and political correctness. This discursive and stylistic repertoire can be elaborated in very different directions, used with varying emphasis and linked 
with political projects on the right and the left. Populism is neither a presence nor an absence but a matter of degree.

Populism claims that we live in exceptional times demanding exceptional measures. Affective practices and emotional responses are essential for populism's success. It depends on affective investment in politics and faith in the idea of returning power to the people. However, populism is also based on affective disinvestment from representational politics and a lack of faith in political systems. (Brubaker, 2017a: 380)

M ost researchers (e.g. Aslanidis, 2016; Brubaker, 2017a; b; Freeden, 2017; M udde and Kaltwasser, 2012: 9) agree that populist thinking is chameleonic, malleable and usually attached to a leftist or rightist ideology or a hybrid version. The Finnish populist movement, like many European populist movements, is highly intertwined with nationalism. In national-populism thought, the horizontal and vertical dimensions of the borders between 'us' and 'them' come together. Those entitled to belong to the 'people' are the 'ordinary people' who present the right nationality and way of life. Nationality is inherited; official nationality is not adequate as national-populists see different origins, even over generations, as a threat to the nation-state. In the vertical dimension, the elite political and economic rulers are represented as distanced from the hardships of 'real people'. Horizontally, they are understood as culturally deracinated, rootless cosmopolitans who do not belong to the nation-state. National-populists suspect that the elite is more interested in the rights of minorities and distant others than the majority and the people of the 'nation'. Nationalpopulists believe that the elite's opening of borders and protection of immigrants will ruin the nation, while those who try to save the nation-state from the elite's mistakes are accused of racism (Brubaker, 2017b).

The national-populist ideology penetrates the material analysed in this study. The nationalism in our case is extreme and views the success and rescue of the nation as the sole purpose of action without any other moral preconditions (Audi, 2009). As in several other European nationalpopulist movements (Alessio, 2015; Berntzen and Sandberg, 2014; Betz and Johnson, 2004; Ekman, 2014; Keskinen, 2013), the 'people of the nation' has a highly exclusionary meaning. These movements are anti-Islamic, racist and mostly extreme rightist. In addition to the elite, leftists, the 'tolerant' and all people not seen as 'white' are treated as threats to the nation-state and depicted hatefully.

European national-populist movements have become very skilful at using social media to spread their ideologies nationally (Ekman, 2014; Koster and Houtmann, 2008; Tateo, 2005) and transnationally (Caiani and Kröll, 2015; Caiani and Wagermann, 2009; Doerr, 2017). Social media matches the populist discursive and stylistic repertoire that simplifies, dramatises and emotionalises political discussion (Brubaker, 2017a). On social media, national-populists can frame public issues in their terms, construct threats by accumulating anecdotal evidence, self-socialise and show their loyalty by liking and sharing, and confirm their worldviews with ideologically consistent content (Krämer, 2017). Images are an especially important tool for transnational social media activity as they can overcome language barriers.

Image circulation is an affective practice. It is an activity that is spurred by emotions and feelings, which are essential for the formation of political identity. In our case, image circulation is a national-populist political activity through which its supporters are able to connect with similar- 
minded people: to tell their opinion, express their urge to belong to this group, and to create and strengthen group's shared political view. Circulating images indicates that the sharer has invested her/his affective attention to these particular images, and used her/his time for political action that $\mathrm{s} /$ he considers meaningful. Images that are most commented, have received most reactions, or are most often circulated, have been such that they have been most strongly approved in this group. These images have best corresponded to the shared identification (Wetherell 2015: 155) and to collective meaning-making (Nikunen 2015:3) of the national-populist movement.

Images have more power than text to catalyse collective affects and feelings because they can convert the abstract, distant and complex into the concrete, proximate and simple with affective significance for large audiences (Proitz, 2018). Images bind a network of associations and affects in time and place and can be tracked and responded to. Affective judgements and understandings of the identities can be converted into images and associated dispositions, expressions and connections (Carah, 2014). Social media platforms on which image sharing is an essential function have become homes for national-populist movements.

\section{Circulation of images in online spaces}

In social science, the circulation of images, both still and audiovisual images, has been investigated from numerous perspectives. Some studies view image circulation as a prominent use of media (Carah, 2014; Highfield and Leaver, 2016), and others scrutinise circulation of memes, often following reversioning of certain themes (Bayerl and Stonow, 2016; Boudana et al., 2017; KliglerVilenchik and Thorson, 2016; Topinka, 2018). Many studies treat image circulation as platform politics from the user's perspective: the researcher seeking images related to a particular public case analyses the material that platforms offer (see Matamoros-Fernandez, 2017; Sumiala and Tikka, 2011). In another method, the research tracks and follows one or several images or videos by either manually searching particular sites (Doerr, 2017; Kraidy, 2012) or using reverse search engines (Horsti, 2016). In a large-scale pilot study, O'Halloran et al. $(2016,2018)$ used multimodal analysis visualisation to investigate where images of a particular journal were republished and how they were recontextualised. Similarly, Pearce et al. (2018) developed various methods from network analysis to image sorting to identify similar images and their circulation in online communities.

Extensive studies on image circulation in computer science have found that image resharing, which drives circulation, is rare. In 2013 , only about $5 \%$ of images uploaded to Facebook were reshared or circulated (Dow et al., 2013). Some images are reshared frequently, and others only a few times; image resharing, therefore, follows the power-law distribution. Dow et al. (2013) showed that high levels of image resharing on Facebook occurs through two mechanisms. First, well-known, highly followed users upload images that their immediate followers reshare. Second, relatively unknown individuals upload images reshared in a more viral way. Both mechanisms can generate similar levels of resharing, suggesting that prominent social roles are not the only explanatory factor; the content and its attributes also are. However, Dow et al. (2013) used only a single mechanism to observe image resharing, limiting the analysis to, for instance, reuploaded versions of the same images. Due to various affordances, social media platforms with such limitations may challenge these results (cf. Pearce et al. 2018; Gibbs et al., 2015). 
Recently, researchers examined content circulation within single platforms. Zannettou et al. (2018) found that most images in a dataset of 14,000 memes (on meme-collection platform) emerged from platforms such as YouTube, 4chan and Twitter. These platforms benefit from fringe communities, who use them to share politically motivated memes. Researchers have argued that platform and design and users cultures also impact image circulation as an activity (Gibbs et al., 2015; Pearce et al. 2018). These findings demonstrate the important roles of platforms in image circulation.

\section{Methods}

Research on affective practices 'may sketch out [the] affective canon of a particular group or community', and moreover, the 'shared emotions across a particular social media site [...] illustrate the collective dimensions of affective meaning-making' (Nikunen, 2015: 3). We understand the number of reactions and comments and the time of circulation as evidence of the collective nature of emotions and shared interpretations of images.

Following Wetherell (2012), we sought to illustrate the process in which affects and circulation come into concrete being. Affect does not just float around, but there are actual bodies and social actors who negotiate, evaluate and communicate when images are circulated. Furthermore, if affect becomes more powerful through its circulation, as Ahmed (2004a) has proposed, then it is necessary to know what kind of imageries receive the most responses and how they move among sites. Understanding what kind of communicative acts are behind the transmission and circulation of national-populist images, therefore, is significant.

\section{Data selection and collection}

As the social media platform studied in this research on the affective economy, we chose Facebook as it is widely used in Finland, and its algorithmic system is known to favour image sharing. We collected data from ten Finnish national-populist Facebook communities (pages or groups ${ }^{1}$; see the Appendix). These communities are important forums for national-populist discussion in Finland, where we chose to study national-populist image uses for several reasons. First, Finland has high use of social media and the Internet, making this infrastructure readily available to social movements (Castells and Himanen, 2002; Official Statistics of Finland, 2019). Second, nationalism-populism and political polarisation, although historically low, have seen rapid growth, most recently in response to the 2015 spike in asylum seekers (e.g. Bengtsson et al., 2014; Palonen, 2018). Third, the main language of $90 \%$ of people in Finland is Finnish, which is not spoken in any other country. Thus, Finland presents an interesting example of how social media images may transcend language borders even among communities that highly value nation and national languages. The developed communication infrastructure serving image circulation,

\footnotetext{
${ }^{1}$ Facebook groups and pages provide different affordances. Groups focus on user-generated content, while pages highlight page managers' content production. We use the term community to refer both and mention groups and pages separately to refer to a particular type of community.
} 
combined with a nearly monolingual culture and the rising popularity of national-populism, make Finland an interesting example for studying image circulation: where do national-populist communities draw their images?

With slight differences in emphasis, the national-populist communities articulate a fairly coherent discourse blaming the government and European Union for immigration. Immigration is believed to introduce to the home country with harmful, alien, especially Islamist, influences that cause violence and terrorism. Immigration requires financial investments that otherwise would have gone to needy countrymen, such as veterans and the unemployed. The size of the communities varies from nearly 64,000 users (Soldiers of Odin) to only 260 (Rajat kiinni II or Shut the Borders II). M ost have a few thousand members.

All the communities were public, so we collected posted content through the Facebook Graph API (an application programming interface). We had access to all these groups' posts, images and metadata, such as time of posting. Data were collected from February 2009 to February 2017. However, most images were posted in late 2015 and early 2016. We collected 54,688 posts and 7,607 images. All the posts, comments, metadata and images were downloaded for analysis. The investigated images included memes, photographs, cartoons and all other visual material.

The content studied was public and visible to all Facebook members. However, we acknowledged that studying national-populism could be considered sensitive by members of these communities, even when they were publicly visible. We sought to anonymise the details of the study setting and participating individuals to balance the questions of publicness and the communities' expectations of privacy. We, therefore, argue that this study follows ethical practices (M arkham et al., 2012). Furthermore, at the time of collection, the data were available through Facebook API. Facebook recently limited data access to protect individual privacy and, for example, limit profiling. This data set was collected for academic research to analyse the non-identifiable dynamics of communities, so we argue that it may be used for academic publications. This research was exempt from institutional review in the authors' country as we studied public behaviour and actions without intervening in them. Instead of approval from an external institutional review body, research ethics in the authors' country emphasise the ethical decisions made by individual researchers based on ethical best practices, such as AolR ethics guidelines (TENK, 2018).

\section{Discourse-historical analysis of the images}

Reactions, likes, comments and sharing indicate that user has invested her/his affective attention to these particular images, and used his/her time to react some way: liking, writing a comment or possibly sharing the image further. These images have been 'sticky' enough to grab users' attention in the constant flow of social media content and made them react (Paasonen, 2016). Stickiness is based on the repetition of associations that become intrinsic to this particular a sign or image and makes possible the accumulation of affective value of an image (Ahmed, 2004a: 8992). These interpretative associations may vary across communities and their ideologies and affects: in this study, it is meaningful that the images are shared among national-populist Facebook communities as part of their interpretative practices. In other words, historically produced interpretative associations are always part of images, and their repetition within certain affective-discursive practices makes them more and more affective. As Wetherell (2012: 159) says, 
it is the history of affective practice over time and the history of its entanglements with other social practices and social formations that creates value to affect. When certain kinds of images are posted and shared repeatedly, the gain more and more affective value (Ahmed 2004a). This is how images become powerful enough to catalyse and mobilise affective reactions (Ahmed, 2004a; Proitz, 2018: 551, 557; Wetherell et al., 2015: 57).

The discourse-historical perspective on images is crucial because of the historical dimension of affectivity and its entanglements with other social practices and formations (Wetherell, 2012: 159). Discourse-historical analysis explains why images contain culturally and politically shared perspective that provoke affective reactions. Discourse-historical analysis emphasises the relevance of context to the analysis of texts and images and considers 'intertextual and interdiscursive relationships between utterances, texts, genres and discourses, as well as extralinguistic social/sociological variables, and the history of an organisation or institution, and situational frames' (Reisigl and Wodak, 2009: 90). In the analysis, images are intertextually connected to related genres of discourse and strategies of information and history (Leeuwen and Wodak, 1999).

We selected the most commented, reacted and circulated images for further investigation and examined five images for each criteria for each community. From these, we chose three images to illustrate the study material and expand the discourse-historical analysis. Our analysis considered an image's genre, related comments (Image 2) or text (Image 3), as well as the situational frame (the sharing of the image in a national-populist Facebook community), the history of Finnish society and European nationalist thought, and the relationship of national-populist ideology to what the image depicted.

\section{Tracking image circulation between national communities}

To identify which images in our sample circulated, we needed to find when the same image appeared in several communities in our visual big data. We used image fingerprints, a computer science and digital forensics method to characterise images' appearance. We transformed all the images to fingerprints and searched for images with the same fingerprints to identify similarly appearing images. For each image, we computed a fingerprint (technically, a perceptual hash) that transformed it into a non-meaningful textual representation. Due to the computation method of fingerprinting, images that appear similar ('perceptual equality') have the same fingerprints (Jablons, 2017; Venkatesan et al., 2000; Zauner, 2010).

Based on these fingerprints, we compared two images and identified if they were the same. This analysis approach had limitations. We could not detect various image manipulations, such as rotations, created collages and added captions. Consequently, our analysis of image circulation did not include images with the same background but different text (as is common in memes whose captions are changed). We also applied computationally simple average hashing to images, despite the availability of more advanced methods for image fingerprinting (e.g. Ou and Rhee, 2010) and crowdsourcing approaches. This simple approach might have limited the findings but was appropriate for an initial investigation of large-scale image circulation using visual big data analysis methods. Due to these limitations, our results provide a lower bound of image circulation. Future researchers might relax the definition of similarity from exact match to perhaps a $90 \%$ match or 
apply more advanced computational methods to study image circulation on a larger scale. However, our findings well represent the vastness of image circulation, and a lower the match would increase the number of circulated images.

To examine image circulation, we conducted community- and individual-level analyses. At the community level, we examined how the same images appeared in different communities. Shared Facebook images have timestamps, so we could analyse the temporal dynamics of image sharing, observing an image shared first in one community and then another community. Second, in Facebook groups, each image carries the identity of its sharer, which allowed identifying which actors shared images. Both the timestamps and the identities were used to develop networks, first, between communities and, second, between persons and communities.

\section{Transnational image circulation}

In this study, we used Incandescent, a meta reverse image search service (http:// incandescent.xyz/), to search for online images similar to those we had collected from the communities. Incandescent uses Google, Bing, Baidu and Yandex reverse image searches and returns the URLs of all the images found. Manual inspection, however, found that the reverse image search was inaccurate: many images indicated as the same did not look similar. We needed to identify exact matches of the images, so we used image fingerprinting to identify the same images. The total sample contained more than 250,00 potential images from 73,000 domains. Closer examination revealed that many images were not similar to the search images, so reverse image search technology also seemed to return many non-relevant images. Consequently, we downloaded all the potential images and compared them with the images collected from the Facebook communities by running image similarity analysis to determine exact matches.

Finally, to explore the transnational dimension, we considered the language used on the pages of the images. Applying automatic language detection analysis, we examined the main site of each domain and its language to identify Finnish sites (main page in Finnish) and non-Finnish sites (main page in a non-Finnish language, e.g. Russian, Swedish, English). The list was manually curated to highlight large global platforms (e.g. Instagram and Pinterest) as on these platforms, the language of the site did not correctly indicate potential users' nationalities.

Network of image community and sites where the image was found were then visualised using force-layout to examine their structural properties. Statistical analyses were performed based on observations from visual analysis following the principles of data-intensive research (Kitchin, 2014). Applying visual big data analysis was hindered by validity and contextualisation challenges common with text data or any form of big data (e.g. boyd and Crawford, 2012; Grimmer and Stewart, 2013). For example, not all images returned by the reverse image search represented the searched image, so fingerprinting was conducted to increase validity. Unfortunately, the historic paths regarding how images have occurred on different sites still cannot be traced, so our analysis could not define the directions of circulation. It is crucial to develop new methods to do so to understand the ways in which right-wing political movements operate on social media. However, from the perspective of users who see the constant flow and circulation of images, their origins might not be so important. 


\section{Images mobilising affectivity}

In the research material from Finnish national-populist Facebook groups, the image that received the most reactions (e.g. thumb icons) was posted to the Soldiers of Odin Facebook group. This image presents a demonstration by this national-populist group in Tampere, Finland, in February 2016. The Soldiers of Odin Facebook group is clearly the largest (over 60,000 members), so in this sense it is unsurprising that this image received the most reactions $(5,167)$ of the analysed images. However, Soldiers of Odin is not the most active community: three other communities have significantly more posts and comments despite their smaller size (see Appendix).

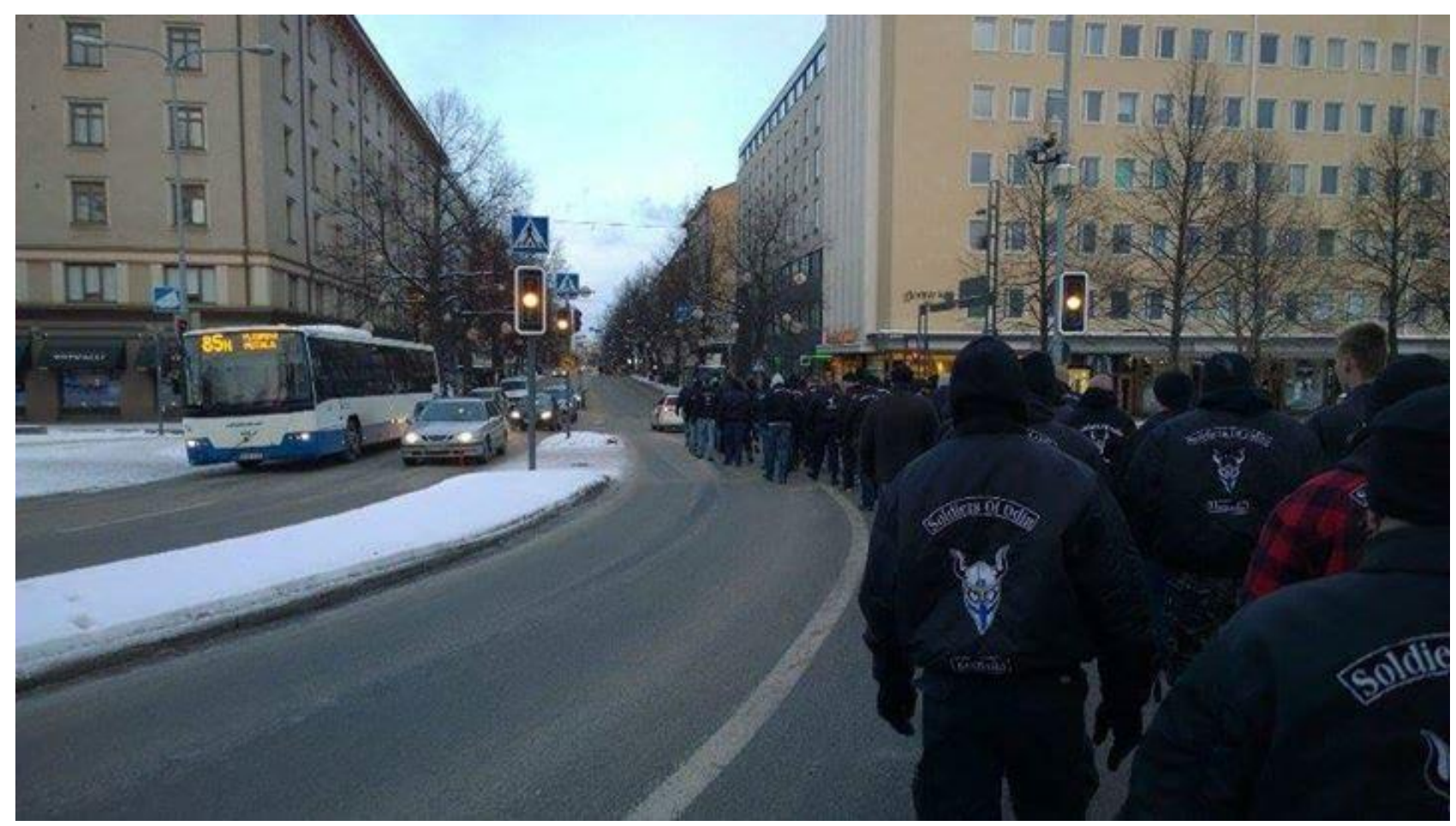

Image 1: Image with the most reactions. The image was posted to the Soldiers of Odin Facebook group in February 27 in 2016.

Image 1 represents members of Soldiers of Odin as marching troops, and, like many Soldiers of Odin group photos, includes only men. With their uniform black jackets, they resemble an army. The rear perspective hides the marchers' faces and physical differences, creating an effect of nearly absolute uniformity. The photo is intended to give the impression of quiet strength, decisiveness, discipline and domination. It evokes the masculine ideals of service and sacrifice to the fatherland and male camaraderie in war, which developed during the First World War in Europe and peaked with fascism, which stressed the warrior qualities of masculinity (M osse, 1996: 130-142, 168-172).

As in the fin de siècle and fascist Germany (M osse, 1996: 139-140), Finnish veteran organisations have had intense cultural impacts on the strong intertwining of masculinity, patriotism, nationality and religion. After the Second World War, soldiers and their sacrifices received praise for preserving Finland's independence. In the following decades, the cultural fusion of patriotism, nationalism and admiration for veterans was supported by official state and church rituals, numerous books and films, and public recollections of veteran organisations. These 
commemorations have repeatedly emphasised the boundless unity and perseverance of Finnish forces (Kivimäki, 2012). These public and collective remembrances have created an emotional national narrative (White, 2000). This historical context gives affective force (Ahmed, 2004; Sakamoto, 2015) to the image of a unified, marching troop and appeals to those who accept the narrative produced by commemorations. The image and various studies on extreme nationalist movements in Europe (Ekman, 2014; M iller-Idriss, 2017) show that the image of man-as-soldier is essential to the national-populist ideology, and its appeal among the supporters of Soldiers of Odin further proves that.

Image 2 received the most comments. It and was also posted by the Soldiers of Odin Facebook group. It shows the freshly crowned $M$ iss Helsinki with the runners-up in January 2017. From a representational perspective, the image itself has no peculiar features; it is a typical press photo from a beauty contest.

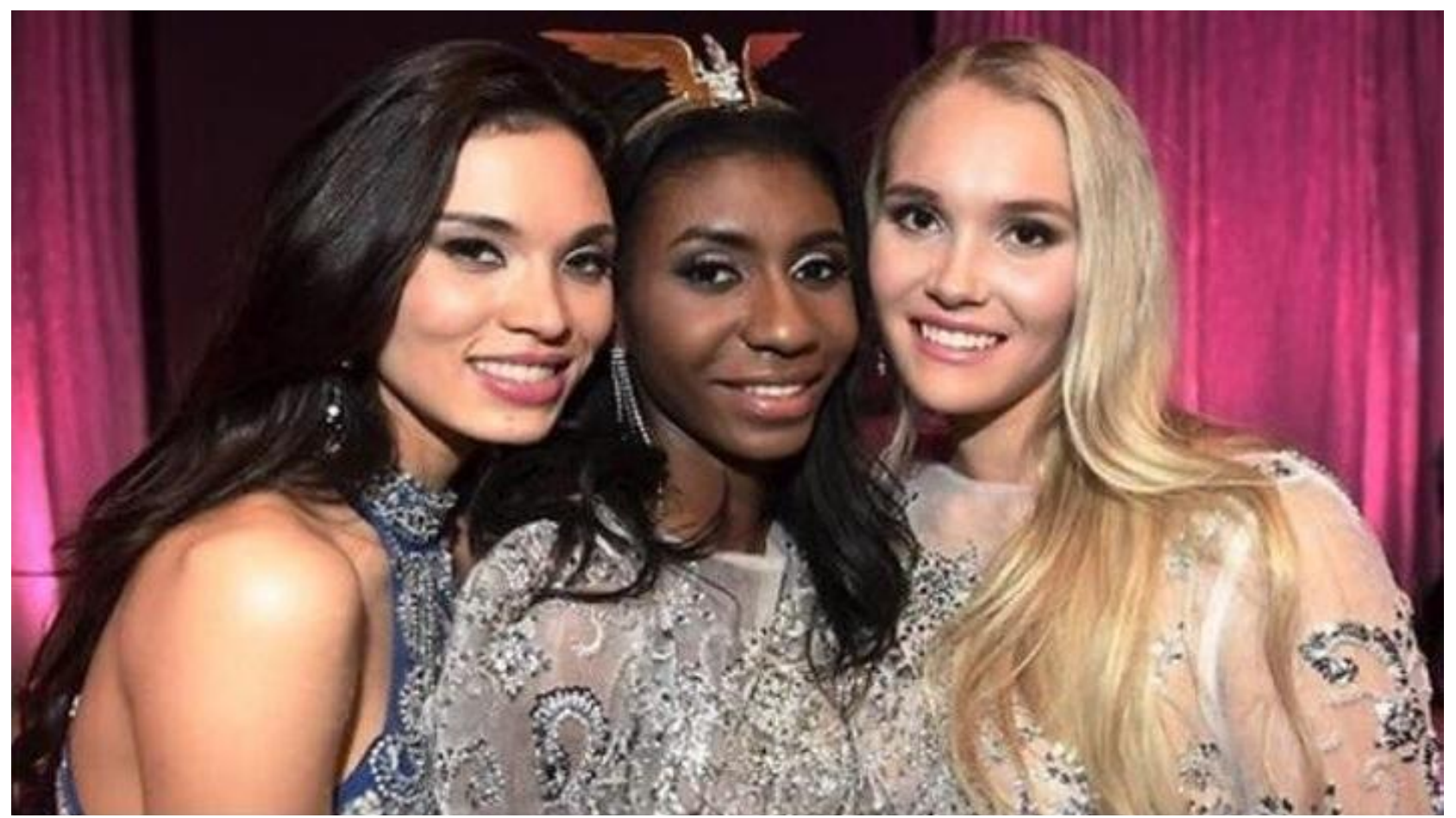

Image 2: The most commented image. The image was posted to the Soldiers of Odin Facebook group in February 7 in 2017.

Although often regarded as insignificant, women's beauty contests have been one prominent site for showcasing the racial purity and beauty of the nation. Beauty contests became popular at the same time as nationalist movements flourished in the 1920s and 1930s, and consequently, beauty contestants became the 'frontline soldiers in the battle of cultures' (Grout, 2013: 47). In Europe and North America, the concept of beauty that has represented the ideal characteristics of the nation has been strongly tied with the ideals of superiority and ideality of whiteness (Cisneros and Nakayama, 2015; Mattsson and Petterson, 2007).

While the cultural relevance of beauty contests has diminished, they remain a site where questions of nationality, national identity and race are negotiated. In the past decade, the selection of non-white contestants as the winners has prompted racist social-media attacks in 
United States (Cisneros and Nakayama, 2015), in France (Pheiffer, 2013) and in Belgium (Vanpevenaege, 2018). Cisneros and Nakayama (2015) noted that much of the debate on beauty contestants constitutes an 'old' type of racist discourse in contrast with colour-blind racism. The old racist discourse explicitly holds that different 'races' exist in a hierarchy. Accordingly, the discussion on the new M iss Helsinki on the Soldiers of Odin's Facebook group was highly unanimous, either explicitly or ironically declaring her unfit to represent 'Finnishness' because of her skin colour and mocking her appearance either as manly or ape-like. The constant repetition of same kind of comments by various users indicates that the prime function of commenting is to manifest one's belonging to the group and to its political ideology, and to connect with other supporters.

Despite the uniform nationalist-racist discourse, the discussion was very transnational. The post related to the image was written in English, indicating that the original sender, who probably was Finnish, wanted to reach international audiences. Although most comments were in English (50\%) or Finnish (28\%) or consisted of signs such as emojis or question marks $(9 \%)$, comments were also written in Czech, Russian, Swedish, German, Estonian, Italian, French, Polish, Hungarian and Spanish. Only the Russian users received negative comments from some Finnish members because of the language used. Some English comments appeared to be from North American members as their comments lamented Europe's decline that they saw the new M iss Helsinki as embodying. However, caution should always be exercised when drawing conclusions based on anonymous Facebook discussions.

Image 3, which was the most circulated among the chosen Finnish national-populist FB groups, is a modification of Finland's coat of arms. The official coat of arms has a red background and yellow lion, but the modification has the same colours as the Finnish flag: blue and white, which are generally considered to be 'national' colours. The modification has additional text: 'Finland first. We will not surrender, we will not give up'. It is the logo of the national-populist group Finland First! (Suomi Ensin!). This image was sent to the group M inun Suomeni ON Sinivalkoinen (M y Finland IS Blue and White) seven times, Suomi Ensin! Foorumi (Finland First! Forum) six times and Suomi Ensin! -aktivistipalvelu (later Suomen Kansa Ensin! [Finland's Folk First!]) once. Sharing and circulating the same image for multiple times shows how image circulation is an established affective practice through which supporters are able to take political actions: let their ideological stance to be visible, connect with other supporters, and to create and sustain the shared political identification and collective meaning-making. 


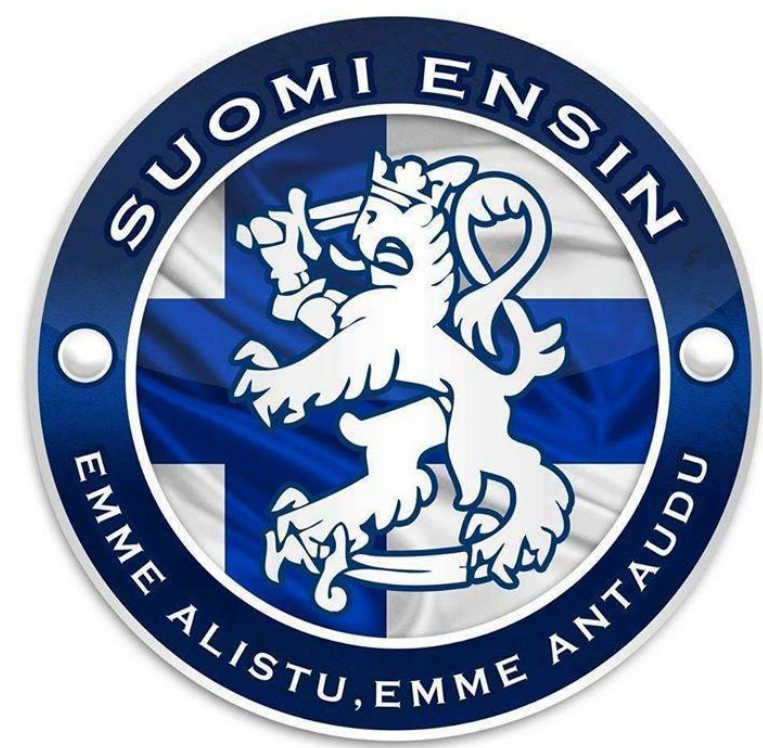

Image 3: The most circulated image. The image was shared and re-shared altogether 14 times during the research period: first time in M inun Suomeni ON Sinivalkoinen [M y Finland IS blue and white] in 29 July in 2015 and last time in Suomi Ensin! -Foorumi [Finland First! Forum] in January 6 in 2017.

The image has clear, easy-to-share message. The blustery text creates the sense of constant battle against the enemy, recalling the Italian and German fascist ideology of the 1920s and 1930s to which the idea of continuing to fight real or imagined domestic and foreign enemies was central (M osse, 1996: 177-180.). The idea of constant threat from inside the state (e.g. immigrants and other 'suspicious' groups) and outside powers (e.g. the EU) are typical of extreme nationalist movements throughout Europe (Bowman-Grieve, 2009: 993-995; Ekman, 2014; Salmela and Scheve, 2017: 577-578).

Within their publication contexts, all three images promote a sense of danger to the survival of the nation and for the feeling that this danger should be fought against. Through their circulation and surrounding activity (e.g. comments and reactions) that make them more visible on Facebook, the images have gained affective force. As previous studies suggested (Capelos and Demertzis, 2018; Salmela and Scheve, 2017; 2018), emotions such as anger, fear and resentment among supporters are essential for the success of national-populist movements. Our study shows that Facebook is an effective tool to spreading such images that mobilize such emotions both nationally and transnationally. 


\section{Spread of images between national communities}

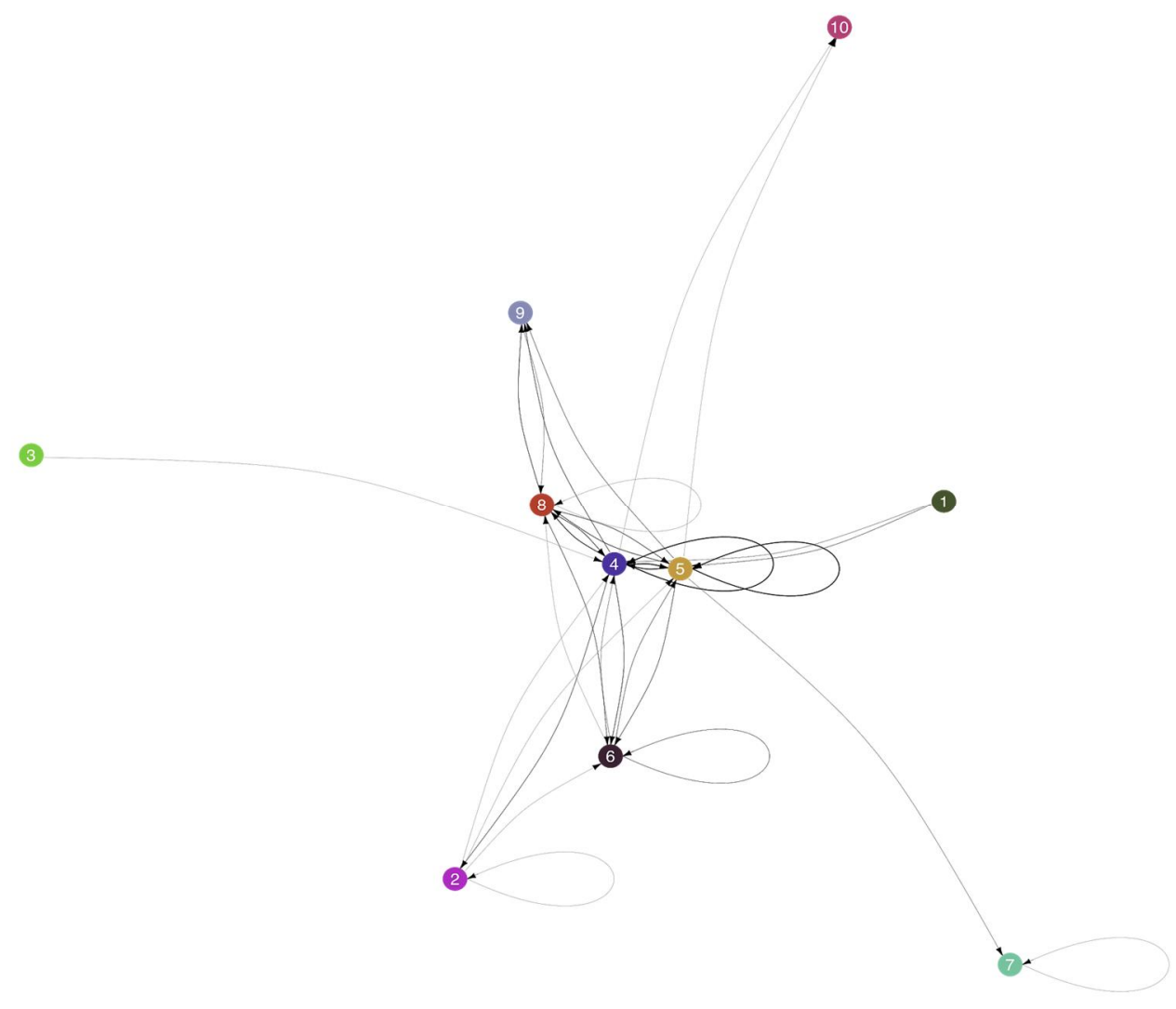

Figure 1a: Image sharing among national communities. The width of the tie indicates the total volume of image resharing.

We explored the circulation of images among Finnish national-populist communities by conducting computational analysis at the community and individual levels. Figure 1a shows that communities 4, 5, 6 and 8 are central to the image network and actively share images.

Communities 4 and 5 seem to be the origins of circulated images seen in communities 2, 6, 7, 8, 9 and 10 , suggesting that they are circulation hubs actively supporting image circulation in other communities. These two communities are also among the largest in terms of content produced and members engaged, and their large membership partly explains their critical role in content circulation.

The less central communities do not engage in similar image sharing activity. Communities 2 and 7 often reuse images and send them to the community again. Communities 1 and 3 do not share images sent to other communities, but their images are shared again in communities 4 and 5 , which possibly communicate them to community 9 , with which they engage in much activity. Community 10 receives images from other communities but does not exchange them.

Figure la also shows that many communities reshare images within themselves. These images seem to have enough affective power to interest people who have already seen them. This 
behaviour suggests an interesting dimension of image circulation for further research: how images are reused in their original context.

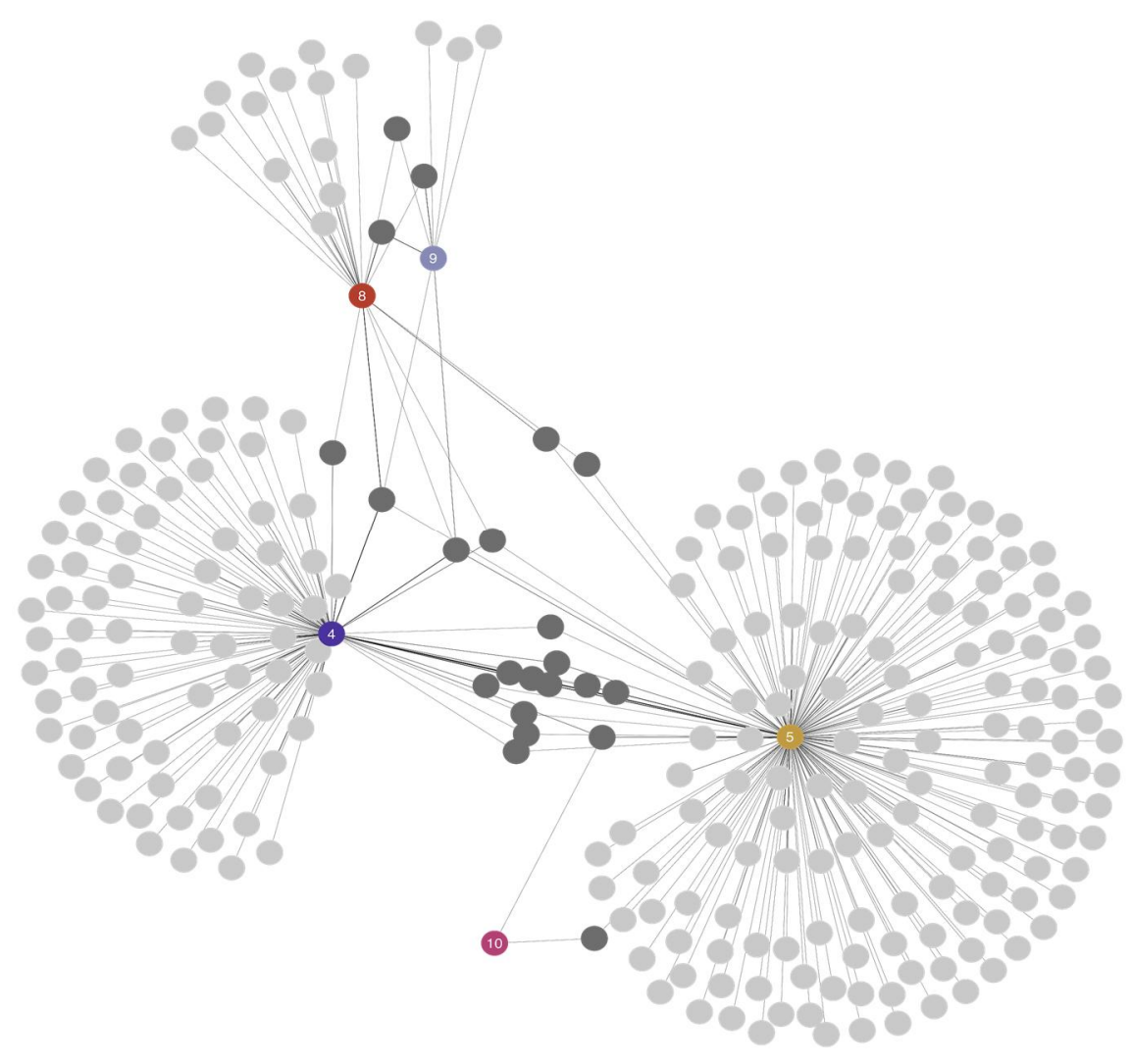

Figure $1 \mathrm{~b}$ : Individuals and how they share images with national communities. The width of the tie indicates the total volume of image resharing. Due to data restrictions, we could analyse only Facebook groups.

Regarding image circulation at the individual level, a small number of active members has powerful impacts. Figure $1 \mathrm{~b}$ shows how individual users are involved in image sharing. M ost users (light grey) only share similar images with a single group. A few users (dark grey) share the same images to more than one group. We observe that individual users active in a particular community group share most of the images. Image circulation activity thus is mostly not activated by a few persons but by the community at large. It, therefore, can be considered to be an organic activity.

However, users who bridge communities more actively circulate images. The mean number of images circulated is 1.75 for users active in only one community but 3.84 for users active in more than one community, normalised by the number of communities in which they are active. The difference is significant $(p=0.001, W=1,538$ ). Figure $1 b$ shows that while individuals active in only one community play an important role in image circulation, a small subset of super-engaged community members contributes significantly to these activities, as has been well established in many online environments (e.g. Graham and Wright, 2014; M aia and Rezende, 2016). Superengaged posters shared approximately $47 \%$ of the images, and the posters active only within one group shared $53 \%$. 


\section{Images in the transnational perspective}

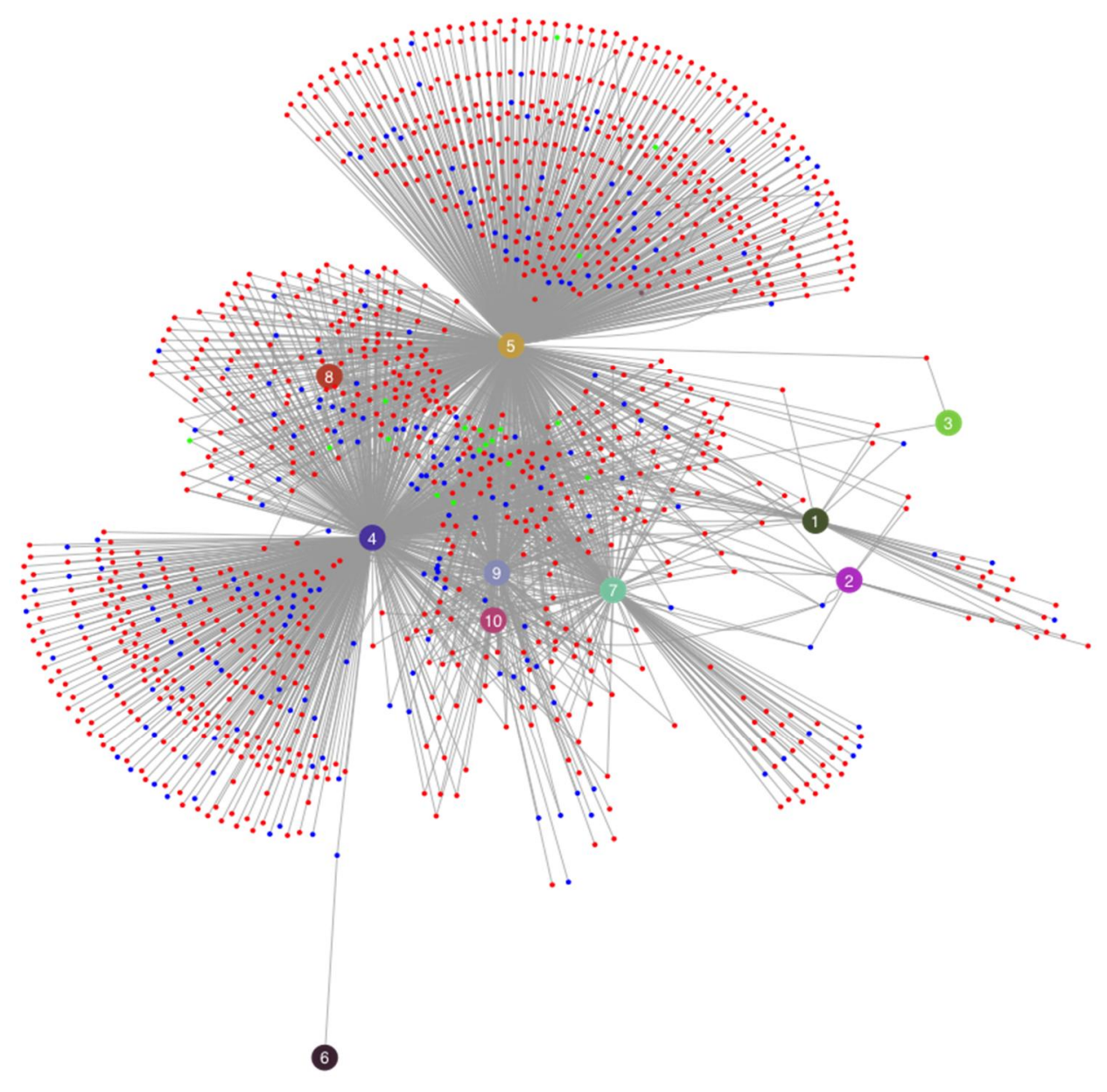

Figure 2: Selected communities and same images in Finnish (blue), non-Finnish (red) and global (green) platforms.

When exploring the movement of images between global and national communities, we noticed that our analysis of image sources reflected previous findings on linking behaviour: many communities have specific, unique websites, but large content distribution sites also emerge (Figure 2). Most websites are non-Finnish websites (red, e.g., bbc.com, feministisktperspektiv.se, biasedbbc.org). Images from Finnish websites (blue, e.g., uusisuomi.fi) and global platforms (green, e.g. Pinterest, imgur) are in the minority. The network also shows that large content distribution sites, or hubs, are user-generated content portals at the global level (e.g. Instagram, Pinterest and Twitter) and the national levels (e.g. Ylilauta, a Finnish discussion board similar to 4chan).

Our first observation is that many images used and circulated in Finnish national-populist communities are shared transnationally. This implicates that these images appeal to shared cultural and political understandings of users, transcending national borders. Furthermore, 
national-populist movements, although motivated by local concerns, are able to use material produced transnationally to strengthen their supporters' ideological stances.

In a second observation, global platforms are critical to image circulation. We examined how many communities produce content (the degree of the edges in the network) and how much content is imported from other sites (the weight of those edges in the network). As seen in Table 1, an image also present on a global platform is shared more often on communities. Images from Finnish sites seem to be shared slightly more often in communities than images from non-Finnish sites. Although the differences and the effects are small, the differences are significant (Kruskal-Wallis $\chi^{2}$ test $64.927, d f=2, p<0.001$ ). Similarly, the number of images taken from sites (strength) is seen to have effects. Again, global platforms are the source of more images than Finnish and nonFinnish sites. Finnish sites, however, display more of the same images than non-Finnish sites. Again the differences are significant $(245.95, \mathrm{df}=2, \mathrm{p}<0.001)$. In addition to the pivotal role of global platforms, we show that Finnish sites and non-Finnish sites have similar degree in the network, indicating that both are often used as sources.

\begin{tabular}{|c|c|c|}
\hline & Degree & Strength \\
\hline Finnish sites (blue) & 1.6 & 16.4 \\
\hline Global platforms (green) & 5.1 & 341.7 \\
\hline Non-Finnish sites (red) & 1.5 & 5.21 \\
\hline Statistical difference & $p<0.001$ & $p<0.001$ \\
\hline
\end{tabular}

Table 1: M eans of degrees and strengths of different nodes in the network

Our results show that global platforms are important in image circulation. Both the number of Facebook communities to which each global platform provides images (measured through degree) and the number of images taken from each site (measured through strength) are higher than for Finnish sites and non-Finnish sites. Similarly, recent research on visual materials has suggested that studying these platforms is critical (Gibbs et al., 2015; Pearce et al 2018). Furthermore, the recent emergence of critical platform studies could prompt further investigation of the design and implementation of global platforms. What gives global platforms such an important role in this network? Previous research cited the lack of gatekeeping and relatively easy setup process in social media (e.g., Kwon et al, 2012), but the platforms' practices could also have a role (Matamoros-Fernandez, 2017). Further research could scrutinise the differences of global platforms involved in national-populist image circulation to describe in detail the mechanisms in this complex process.

Some studies have stressed the Internet's central role in establishing transnational networks between North American and certain Central and Southern European countries (Caiani and Kröll, 2015; Caiani and Wagermann, 2009; Doerr, 2017). Our study confirms this finding and but also concretely describes the essential role of image circulation and its established practices in these networks' operation. Furthermore, our analysis gives empirical proof of both the quantity and the geographical vastness of image circulation among national-populist movements. Based on our 
findings, it is reasonable to suspect that the spread of the same images from one country to another helps right-wing and national-populist organisations unify their ideology transnationally and increase their messages' affective force, thereby strengthening their political movement on a global scale.

\section{Conclusions}

Social media is increasingly based on visual communication practised within specific social settings or audiences (Schreiber, 2017). Images have become a powerful part of political communication. In our study, we demonstrate how images help to tie together the national-populist social network: through image sharing, commenting and reacting, supporters are able to create and sustain connections with each other, to feel united and express their political identity, political emotions and belonging. The repetitious nature of users' comments and the circulation of same images indicates this social and political function. In addition, images work as material for the affective-discursive practices in which emotional, nationalistic narratives from past are linked with current events, present political concerns, and shared feelings. Thus, image circulation has become an established affective practice among the national-populists, and national-populist thinking is effectively spread through images that catalyst and mobilise affects; fear, anger and resentment, that are essential for populist movements.

Our research reveals how images transcend country and language borders to pass among national sites and through global platforms. In this study, the geographical map of national-populist networks spreads from Finland to Britain and from Spain to the United States. The example of Finnish Facebook communities' networks and their image circulation shows that even a country that does not share a common language with any other country is tightly connected to the global network of right-wing and national-populist movements. As example image of $\mathrm{M}$ iss Helsinki shows, nationalist ideology does not prevent transnational connections. To the contrary, despite the uniform nationalist-racist discourse, the discussion itself was very transnational. These images evidently appeal to cultural and political understandings shared by users from different countries.

Global platforms are critical in image circulation and were the source of the most images in our research. National-populist movements, although motivated by local concerns, use transnationally and globally produced and circulated material to strengthen their supporters' ideological stances. Social media platforms, such as Facebook, provide a very useful tool for spreading and circulating these virulent and often racist images shared in communities of similar-minded people.

Moderation of platforms still relies heavily on user reports, so in these communities, users are unlikely to disrupt the circulation of these images.

Methodologically, our research is on the forefront of visual big data research. Using images to understand the global networks of content sharing is a promising approach as images can overcome major language barriers. Tools such as image fingerprinting and reverse image search support theoretically framed social science research. In addition to pure computational analysis, our approach combines computational data analysis with discourse-historical approach. In our work, we used this analysis to connect the theoretical arguments (affectivity) to our computational operationalisation and our motivation for the data analysis (image circulation). This 
approach may be interesting for researchers working with both qualitative and computational methods.

Our work opens opportunities for future methodological work in visual big data. For example, researchers can explore potential variations, such as changes in the meme captions of images. We use the qualitative work to support visual big data, but researchers could also move from computational data analysis to traditional qualitative analysis of images. Furthermore, researchers should seek possibilities to investigate the historical paths and directions of image circulation to better understand the operations of far-right movements on social media. This large-scale computational analysis of image circulation extends the debate on the importance of the affective economy.

\section{Bibliography}

Ahmed S (2004a) Cultural Politics of Emotion. Edinburgh: Edinburgh University Press.

Ahmed S (2004b) Collective feelings. Or, the impressions left by others. Theory, Culture and Society 21(2): 25-42.

Alessio D (2015) The dragon is not always red: the extreme right and ultra-nationalism in Wales. National Identities 17(3): 289-309.

Aslanidis P (2016) Is populism an ideology? A refutation and a new perspective. Political Studies 64(1): 88-104.

Audi R (2009) Nationalism, patriotism, and cosmopolitanism in an age of globalization. Ethics 13: 365-381.

Bayerl PS and Stonov L (2016) Revenge by photoshop: memefying police acts in the public dialogue about injustice. New M edia and Society 18(6): 1006-1026.

Bengtsson Å, Hansen K, Harõarson Óp, Narud HM and Oscarsson H (2013) The Nordic Voter: M yths of Exceptionalism. ECPR Press. Essex, UK.

Berntzen LE and Sandberg S (2014) The collective nature of lone wolf terrorism: Anders Behring Breivik and the anti-Islamic social movement. Terrorism and Political Violence 26(5): 759-779.

Betz H-G and Johnson C (2004) Against the current-stemming the tide: the nostalgic ideology of the contemporary radical populist right. Journal of Political Ideologies 9(3): 311-327.

Boudana S, Frosh P and Cohen AA (2017) Reviving icons to death: when historic photographs become digital memes. M edia, Culture and Society 39(8): 1210-1230.

Bowman-Grieve L (2009) Exploring "Stormfront": a virtual community of the radical right. Studies in Conflict and Terrorism 32(11): 989-1007. 
boyd d and Crawford K (2012) Critical questions for big data. Information, Communication and Society 15(5): 662-679.

Brubaker R (2017a) Why populism? Theory and Society 46(5): 357-385.

Brubaker R (2017b) Between nationalism and civilizationism: the European populist moment in comparative perspective. Ethnic and Racial Studies 40(8): 1191-1226.

Caiani M and Kröll P (2015) The transnationalization of the extreme right and the use of the Internet. International Journal of Comparative and Applied Criminal Justice 39(4): 331-351.

Caiani M and Wagermann C (2009) Online networks of the Italian and German extreme right. Information, Communication and Society 12(1): 66-109.

Capelos T and Demertzis N (2018) Political Action and Resentful Affectivity in Critical Times. Humanity \& Society 42(4): 410-433.

Carah N (2014) Curators of databases: circulating images, managing attention and making value on social media. M edia International Australia 150(1): 137-142.

Castells M and Himanen P (2002) The Information Society and the Welfare State: The Finnish Model. Oxford: Oxford University Press.

Cisneros JD and Nakayama TK (2015) New media, old racisms: Twitter, Miss America, and cultural logics of race. Journal of International and Intercultural Communication 8(2): 108-127.

Crociani-Windland L and Hoggett P (2012) Politics and affect. Subjectivity 5: 161-179.

Da Silva FC and Vieira M B (2018) Populism as a logic of political action. European Journal of Social Theory, April 1, 2018, 1-16. https://doi.org/10.1177/1368431018762540

Demertzis, N (2006) Emotions and populism. In: Hoggett P, Clarke S, and Thompson S (eds) Emotion, Politics and Society. London: Palgrave, pp. 103-122.

Doerr N (2017) Bridging language barriers, bonding against immigrants: a visual case study of transnational network publics created by far-right activists in Europe. Discourse and Society 28(1): 3-23.

Dow PA, Adamic LA and Friggeri A (2013) The anatomy of large Facebook cascades. Proceedings of the 7th International AAAI Conference on Weblogs and Social M edia, pp. 145-154. M assachusetts, USA, July 8-11, 2013. California, USA: AAAI Press.

Ekman M (2014) The dark side of online activism: Swedish right-wing extremist video activism on YouTube. MedieKultur 56: 79-99.

Freeden M (2017) Editorial. Journal of Political Ideologies. 22(1): 1-11. 
Gibbs M, M eese J, Arnold M, et al. (2015) \#Funeral and Instagram: death, social media, and platform vernacular. Information, Communication and Society, 0(0), 1-14.

https://doi.org/10.1080/1369118X.2014.987152

Graham T and Wright S (2014) Discursive equality and everyday talk online: the impact of "superparticipants." Journal of Computer-M ediated Communication 19(3): 625-642.

Grimmer J and Stewart BM (2013) Text as data: the promise and pitfalls of automatic content analysis methods for political texts. Political Analysis 21(3): 267-297.

Grout H (2013) Between Venus and M ercury: the 1920s beauty contest in France and America. French Politics, Culture and Society 31(1): 47-68.

Highfield T and Leaver T (2016) Instagrammatics and digital methods: studying visual social media, from selfies and GIFs to memes and emoji. Communication Research and Practice 2(1): 47-62.

Horsti K (2016) Digital Islamophobia: the Swedish woman as a figure of pure and dangerous whiteness. New Media and Society 19(9): 1440 -1457.

Jablons Z (2017) Evaluating perceptual image hashes at OkCupid. Available at:

https://tech.okcupid.com/evaluating-perceptual-image-hashes-okcupid/ (accessed 31 December 2018).

Keskinen S (2013) Antifeminism and white identity politics: political antagonisms in radical rightwing populist and anti-immigration rhetoric in Finland. Nordic Journal of M igration Research 3(4): 225-232.

Kitchin R (2014) Big data, new epistemologies and paradigm shifts. Big Data and Society 1(1): 112.

Kivimäki V (2012) Between defeat and victory: Finnish memory culture of the Second World War. Scandinavian Journal of History 37(4): 482-504.

Kligler-Vilenchik N and Thorson K (2016) Good citizenship as a frame contest: Kony2012, memes, and critiques of the networked citizen. New Media and Society 18(9): 1993-2011.

Koster W and Houtmann D (2008) Stormfront is like a second home to me. Information, Communication and Society 11(8): 1155-1176.

Kraidy M (2012) Contention and circulation in the digital Middle East: music video as catalyst. Television and New Media 14(4): 271-285.

Krämer B (2017) Populist online practices: the function of the Internet in right-wing populism, Information, Communication and Society 20(9): 1293-1309. 
Kwon K H, Oh O, Agrawal M and Rao H R (2012) Audience gatekeeping in the Twitter service: An investigation of tweets about the 2009 Gaza conflict. AIS Transactions on Human-Computer Interaction, 4(4): 212-229.

M aia RCM and Rezende TAS (2016) Respect and disrespect in deliberation across the networked media environment: examining multiple paths of political talk. Journal of Computer-M ediated Communication 21(2): 121-139.

M arkham A, Buchanan E and Association of Internet Researchers Ethics Working Committee (2012) Ethical decision-making and Internet research: version 2.0. Available at: https://aoir.org/reports/ethics2.pdf (accessed 31 December 2018).

M atamoros-Fernandez A (2017) Platformed racism: the mediation and circulation of an Australian race-based controversy on Twitter, Facebook and YouTube. Information, Communication and Society 20(6): 930-946.

Mattsson K and Petterson K (2007) Crowning M iss Sweden-national constructions of white femininity. NORA-Nordic J ournal of W omen's Studies 15(4): 233-245.

M iller-Idriss C (2017) Soldier, sailor, rebel, rule-breaker: masculinity and the body in the German far right. Gender and Education 29(2): 199-215.

M offit B and Tormey S (2014) Rethinking populism: politics, mediatisation and political style. Political Studies 62: 381-397.

M osse GL (1996) The Image of M an: The Creation of M odern M asculinity. New York/Oxford: Oxford University Press.

Mudde, C \& Kaltwasser CR (2012) Populism and (liberal) democracy: a framework for analysis. In: M udde $C$ and Kaltwasser CR (eds) Populism in Europe and the Americas. Threat or corrective for democracy? Cambridge: Cambridge University Press, pp. 1-27.

Nikunen K (2015) Politics of irony as the emerging sensibility of the anti-immigrant debate. In: Andreassen R and Vitus K (eds) Affectivity and Race: Studies from the Nordic Context. Farnham: Ashgate, pp. 21-42.

Nikunen K (2019) Media, emotions and affect. In: Curran J and Hesmondhalgh D (eds) M edia and Society. London: Bloomsbury. pp. 323-340.

O'Halloran KL, Tan S, Wignell P, Bateman JA, Pham D-S, Grossman M and M oere AW (2016) Interpreting text and image relations in violent extremist discourse: a mixed methods approach for big data analytics. Terrorism and Political Violence 31(3): 454- 474.

O'Halloran KL, Tan S, Wignell P and Lange R (2018) M ultimodal recontextualisations of images in violent extremist discourse. In: Zhao S, Djonov E, Björkvall A and Boeriis M (eds) Advancing Multimodal and Critical Discourse Studies: Interdisciplinary Research Inspired by Theo Van Leeuwen's Social Semiotics. London: Routledge, pp. 181-202. 
Ou Y and Rhee KH (2010) A survey on image hashing for image authentication. IEICE Transactions on Information and Systems 93(5): 1020-1030.

Paasonen, S (2016) Fickle focus. Distraction, affect and the production of value in social media. First M onday 21(10-3): 1-15.

Palonen E (2017) Finland. European Journal of Political Research Political Data Yearbook 56(1): 92-98.

Pearce W, Özkula SM, Greene AK, Teeling L, Bansard JS, Omena JJ and Rabello ET (2018) Visual cross-platform analysis: digital methods to research social media images. Information, Communication and Society 22 Jun 2018, 1-20. https://www.tandfonline.com/doi/abs/10.1080/1369118X.2018.1486871

Pheiffer A (2013) Explaining the racist response to the new M iss France. Elle, 10 December. Available at: https://www.elle.com/culture/career-politics/news/a18782/french-response-tomiss-france-reveals-racism/ (accessed 31 October 2018).

Proitz L (2018) Visual social media and affectivity: the impact of the image of Alan Kurdi and young people's response to the refugee crisis in Oslo and Sheffield. Information, Communication and Society 21(4): 548-563.

Reisigl M and Wodak R (2009) The discourse-historical approach (DHA). In: Wodak R and Meyer M (eds.) M ethods of Critical Discourse Analysis, 2nd ed. London: Sage, pp. 87-121.

Sakamoto R (2015) M obilizing affect for collective war memory. Kamikaze images in Yushukan. Cultural Studies 29(2): 158-184.

Salmela M and von Scheve C (2017) Emotional roots of right-wing political populism. Social Science Information 56(4): 567-595.

Salmela M and von Scheve C (2018) Emotional dynamics of right- and left-wing political populism. Humanity and Society 42(4): 434-454.

Schreiber M (2017) Audiences, aesthetics and affordances. Analysing practices of visual communication on social media. Digital Culture and Society 3(2): 143-164.

Sumiala J and Tikka M (2011) Reality on circulation - school shootings, ritualised communication, and the dark side of the sacred. ESSACHESS. Journal for Communication Studies 4(2): 145-159.

Tateo L (2005) The Italian extreme right on-line network: an exploratory study using an integrated social network analysis and content analysis approach. Journal of Computer-M ediated Communication 10(2). https://doi.org/10.1111/j.1083-6101.2005.tb00247.x.

TENK (2018) Ethical review in Finland. Finnish national board on research integrity. Available at https://www.tenk.fi/en/ethical-review-in-finland (Accessed 26 March 2019). 
Topinka RJ (2018) Politically incorrect participatory media: racist nationalism on r/ImGoingToHellForThis. New M edia and Society 20(5): 2050-2069.

Van Leeuwen T and Wodak R (1999) Legitimizing immigration control: a discourse-historical analysis. Discourse Studies 1(1): 83-118.

Vanpevenaege X (2018) Beauty queen hits back at racist critics. BBC News, 18 January 2018. Available at: https://www.bbc.com/news/av/world-42726615/beauty-queen-hits-back-at-racistcritics (accessed 31 October 2018).

Venkatesan R, Koon SM, Jakubowsk, M H and M oulin P (2000) Robust image hashing. In Image Processing 2000. Proceedings. 2000 International Conference, vol. 3. Vancouver: Institute of Electrical and Electronics Engineers, pp. 664-666.

Wetherell M (2012) Affect and Emotion. A New Social Science Understanding. London: Sage.

Wetherell M (2015) Trends in the turn to affect: A social political critique. Body \& Society 21(2): $139-166$.

Wetherell M, M cCreanor T, M cConville Alex, Barnes HM and le Grice J (2015) Settling space and covering the nation: some conceptual considerations in analysing affect and discourse. Emotions, Space and Society 16: 56-64.

Zannettou S, Caulfield T, Blackburn J, De Cristofaro E, Siriviano, M , Stringhini G and Suarez-Tangil G (2018) On the origins of memes by means of fringe web communities. Available at: http://arxiv.org/abs/1805.12512 (accessed 31 December 2018).

Zauner C (2010) Implementation and benchmarking of perceptual image hash functions. Available at https://www.phash.org/docs/pubs/thesis zauner.pdf (accessed 31 December 2018).

Zelizer B (2010) About to Die: How News Images M ove the Public Account. Oxford: Oxford University Press. 
Appendix: Analysed Facebook communities. The numbers in the table are the same as the numbers in the graphics.

\begin{tabular}{|c|c|c|c|c|}
\hline & Community & Description & Posts and comments & Users \\
\hline 1 & Homma & $\begin{array}{l}\text { [Task] Facebook extension of a Finnish anti- } \\
\text { immigration discussion forum with close political } \\
\text { ties to the Finns Party }\end{array}$ & 1,203 & 3,371 \\
\hline 2 & Lapuan liike & $\begin{array}{l}\text { [Lapua's M ovement] Anti-immigrant Facebook } \\
\text { group named after a Finnish radical right-wing } \\
\text { movement from the 1930s }\end{array}$ & 313 & 649 \\
\hline 3 & Magneettimedia & $\begin{array}{l}\text { [M agnet Media] Newspaper with an established } \\
\text { anti-immigrant agenda }\end{array}$ & 5,176 & 3,509 \\
\hline 4 & $\begin{array}{l}\text { Minun Suomeni ON } \\
\text { sinivalkoinen }\end{array}$ & $\begin{array}{l}\text { [M y Finland IS Blue and White] Conversation } \\
\text { group that promotes Finland as a place only for } \\
\text { Finns }\end{array}$ & 67,018 & 4,349 \\
\hline 5 & $\begin{array}{l}\text { Rajat kiinni! - } \\
\text { Kansanliike }\end{array}$ & $\begin{array}{l}\text { [Close the Borders! Folk Movement] Anti- } \\
\text { immigration movement that aims to close the } \\
\text { borders to asylum seekers, founded in response } \\
\text { to the refugee crisis in the fall of } 2015\end{array}$ & 239,964 & 19,178 \\
\hline 6 & Suomen Sisu & $\begin{array}{l}\text { [Finland's Perseverance] A nationalist and } \\
\text { patriotic Finnish association, criticises unlimited } \\
\text { immigration and multiculturalism }\end{array}$ & 2,120 & 4,181 \\
\hline 7 & Soldiers of Odin & $\begin{array}{l}\text { Anti-immigrant street-patrol group founded in } \\
\text { October } 2015 \text { and registered as an association in } \\
\text { January } 2016\end{array}$ & 31,538 & 63,804 \\
\hline 8 & $\begin{array}{l}\text { Suomi Ensin! } \\
\text { Foorumi }\end{array}$ & $\begin{array}{l}\text { [Finland First! Forum] Anti-immigration } \\
\text { movement aiming to achieve the status of a } \\
\text { registered political party, founded in response to } \\
\text { the refugee crisis in fall } 2015\end{array}$ & 41,920 & 4,379 \\
\hline 9 & $\begin{array}{l}\text { Suomi Ensin! } \\
\text { Aktivistipalvelu/ } \\
\text { Suomen Kansa } \\
\text { Ensin! }\end{array}$ & $\begin{array}{l}\text { [Finland First! Discussion Service, later Finland's } \\
\text { Folk First!] First, a discussion site for group } 8, \\
\text { later an independent group }\end{array}$ & 29,234 & 2,464 \\
\hline 10 & $\begin{array}{l}\text { Rajat kiinni! } \\
\text { Kansanliike II }\end{array}$ & $\begin{array}{l}\text { [Close the Borders! Folk M ovement II] Group } \\
\text { that separated from group } 5\end{array}$ & 1,301 & 259 \\
\hline
\end{tabular}

